\title{
Motivational Interviewing and Return to Work for People with Musculoskeletal Disorders: A Systematic Mapping Review
}

\author{
Fiona Aanesen ${ }^{1} \cdot$ Rigmor Berg $^{2} \cdot$ Ida Løchting $^{1,3} \cdot$ Alexander Tingulstad $^{1} \cdot$ Hedda Eik $^{1} \cdot$ Kjersti Storheim $^{1,3}$. \\ Margreth Grotle ${ }^{1,3} \cdot$ Britt Elin Øiestad ${ }^{1}$
}

Published online: 30 April 2020

(C) The Author(s) 2020

\begin{abstract}
Purpose There is limited knowledge about motivational interviewing (MI) for people on sick leave with musculoskeletal disorders. Hence, our objective was to investigate what research on MI as a method to facilitate return to work for individuals who are on sick leave due to musculoskeletal disorders exists, and what are the results of the research? Methods We systematically searched MEDLINE, PsycINFO, EMBASE, Cochrane Library, CINAHL, Web of Science, Sociological Abstracts, Epistemonikos, SveMed + and DARE \& HTA (covering 1983 to August 2019). We also searched the MINT bulletin and relevant web pages. Eligibility criteria: empirical studies investigating MI and return to work for people with musculoskeletal disorders. Two authors independently screened the records, critically appraised the studies and charted the data using a data extraction form. Results The searches identified 1264 records of which two studies were included. One randomized controlled trial (RCT) found no effect of MI on return to work for disability pensioner with back pain $(n=89$, high risk of bias), while a cluster RCT found that MI increased return to work for claimants with chronic musculoskeletal disorders ( $\mathrm{n}=728$, low risk of bias). Conclusions This mapping review identified a huge gap in research on MI to increase return to work for individuals with musculoskeletal disorders. Registration Current Research Information System in Norway, project id: 635823 (https://app.cristin.no/projects/show.jsf?id=635823).
\end{abstract}

Keywords Motivational interviewing $\cdot$ Return to work $\cdot$ Musculoskeletal diseases $\cdot$ Sick leave $\cdot$ Systematic review

\section{Introduction}

Musculoskeletal disorders affecting joints, bone and soft tissues are the leading cause of disability worldwide [1]. Neck and back pain, osteoarthritis and inflammatory diseases, osteoporosis, bursitis, tendonitis and fibromyalgia are most common [2]. The disorders often have fluctuating symptoms which can reduce work ability [3]. For people living with

Electronic supplementary material The online version of this article (https://doi.org/10.1007/s10926-020-09892-0) contains supplementary material, which is available to authorized users.

Fiona Aanesen

fionaa@oslomet.no

1 Department of Physiotherapy, Oslo Metropolitan University, Oslo, Norway

2 Norwegian Institute of Public Health, Oslo, Norway

3 Research and Communication Unit for Musculoskeletal Health (FORMI), Oslo University Hospital, Oslo, Norway musculoskeletal disorders long periods of sickness absence can be detrimental for wellbeing and hinder return to work, while work and activity can aid recovery [4].

Work participation is dependent upon several social, workplace-related and individual factors [5, 6]. Many different coordinated return to work programmes have been developed to address these factors such as tailored work rehabilitation, case management and collaborative care. These programmes include an assessment of the workers' needs in order to make a return to work plan. The worker can receive a variety of tailored interventions such as medical interventions, education, workplace ergonomics and case management to assist in their return to work. The interventions are usually coordinated and provided by different professions such as physiotherapists, occupational therapists, social workers, psychologists and physicians. Some of the interventions also involve the employer [7]. A Cochrane review from 2017 investigating the effects of return to work coordination programmes versus usual practice on return to work outcomes, including 14 RCTs, showed small to no benefits of such programmes. The evidence from the 
review was low to moderate due to imprecision and substantial heterogeneity between the studies [7].

Motivational interviewing (MI) has been suggested as a suitable method in vocational rehabilitation [8-10]. MI is a person-centred counselling style for addressing ambivalence and strengthen motivation, by exploring the person's own reasons for change [11]. Miller and Rollnick developed MI for the treatment of addictions and define it as 'a collaborative, goal-oriented style of communication with particular attention to the language of change' [11] (p. 29). MI is associated with small to medium effect sizes across a variety of behaviour outcomes [11]. The method has been used to support behavioural change for people with different conditions, including musculoskeletal disorders [12] and chronic pain [13]. MI could be a suitable tool to improve working alliance between caseworkers and people on sick leave [14]. This might be especially important for people suffering from unspecific musculoskeletal disorders who often face mistrust and scepticism related to their health problems $[3,15,16]$. The results from a systematic review from 2017 investigating the effectiveness of MI to facilitate return to work suggested that MI may be an effective intervention, although the authors could not draw any conclusions due to few studies and low quality of the evidence [17]. Five studies were identified in the review, including persons with psychiatric conditions, HIV-positive, drug-involved offenders and people with low back pain. The review included controlled studies and interrupted time series studies.

Several recent publications show that there is a growing interest in $\mathrm{MI}$ in vocational rehabilitation [10, 18]. However, it is unclear what evidence exists related to the use of MI to help people with musculoskeletal disorders return to work. We need an updated review of the study field in order to define future research priorities. The review should include both quantitative and qualitative research, as qualitative research can give information about barriers and facilitators to implementing MI for people with musculoskeletal disorders. Thus, the objective of this review was to map all types of empirical research on MI as a method to help people with musculoskeletal disorders return to work. Our research question was: What research on MI as a method to facilitate return to work for individuals who are on sick leave due to musculoskeletal disorders exists, and what are the results of the research?

\section{Method}

\section{Design}

We followed the guidelines in the Cochrane Handbook for Systematic Reviews of Interventions [19] and the methodological steps for mapping reviews proposed by Arksey and O'Malley [20] and Levac et al. [21]. The systematic mapping review is reported in accordance with the preferred reporting items for systematic reviews and meta-analyses extension for scoping reviews (PRISMA-ScR) [22].

\section{Eligibility Criteria}

Included studies had to address MI as a method to facilitate return to work for individuals on sick leave or disability pension due to a musculoskeletal disorder. All types of empirical studies were included if they were published after 1983 (the year Miller first described the MI method). Studies were included if at least $50 \%$ of the study sample had musculoskeletal disorders, or if results were presented separately for people with these diagnoses. We also wanted to include studies on those giving MI to facilitate return to work for individuals on sick leave with musculoskeletal disorders. Detailed inclusion and exclusion criteria are described in Table 1.

\section{Searches}

An information search specialist developed and performed the searches in collaboration with two of the review authors (RB and FA). The search was from 1983 to February 2019, and updated in August 2019. We searched the following electronic databases: MEDLINE (OVID), PsycINFO (OVID), EMBASE (OVID), Cochrane Library (CDSR, CENTRAL) (Wiley), CINAHL (EBSCO), Web of Science Core Collection (SCI-EXPANDED \& SSCI) (Clarivate), Sociological Abstracts (ProQuest), Epistemonikos, SveMed +, DARE \& HTA (Centre for Reviews and Dissemination). We used different search terms and synonyms for 'motivational interviewing', 'return to work' and 'sick leave'. To identify all eligible studies (including studies with mixed populations), we avoided search terms related to musculoskeletal disorders. We did not apply any methodology search filters or language restrictions in the searches. The first author hand searched all issues of the MINT bulletin (the newsletter for MI trainers), searched the journal: motivational interviewing, training, research, implementation, practice (MITRIP) https://www.mitrip.org, the MINT webpage: https://motiv ationalinterviewing.org and The Norwegian Labour and Welfare Administration (NAV) webpage: https://www.nav. no. We also contacted William Miller and other researchers in the field of MI, to identify ongoing studies or unpublished work. Cited reference searches were performed in Web of science and reference lists of the included papers were hand searched for relevant cited literature by the first author. A detailed description of the search strategy in the databases and other sources is presented in Supplementary material: Appendix I. 
Table 1 Eligibility criteria

\begin{tabular}{ll} 
Participants $^{\mathrm{a}}$ & Receivers of MI interventions: \\
& Musculoskeletal disorders main reason for work absence \\
& On sick leave (part or full time), receiving work assessment allowance or disability pensions \\
& Age group: 18-67 years \\
& Performers of MI interventions: \\
& Person with MI-training using MI to facilitate return to work for participants described above \\
Concept & MI given as a solo intervention, or in combination with other interventions \\
& MI could be given in group sessions, individual meetings or by phone \\
Context & Any context where MI was being delivered \\
Study design & All types of empirical studies \\
Language & English, French, German, Norwegian, Swedish, Danish \\
\hline
\end{tabular}

MI motivational interviewing

${ }^{a}$ Studies were included if $50 \%$ of the study population met the inclusion criteria, or if results were reported separately for participants that met the inclusion criteria

\section{Study Selection}

The information search specialist imported all the search results from the different databases into the citation management software EndNote (Clarivate Analytics, PA, USA) and removed duplicates. All unique records were imported into the screening tool Rayyan QCRI. Two authors (AT and FA) independently screened abstracts and titles for eligibility, using a pre-designed screening form. Selected studies were screened in full text by two authors separately (IL and FA). At both screening levels, disagreements were resolved by discussion and re-examination of the papers.
Figure 1 shows the flow diagram of the study selection process.

\section{Data Charting and Critical Appraisal}

Two authors (MG and FA) independently charted the data from the studies using a predesigned data extraction form. We tested the form and revised it to include more information about study design, participation rate and dropout. The following data were charted from each study: name of first author, year of publication, country, study design, context, study sample/population, participation rate, dropout rate,
Fig. 1 Flow diagram of screening process

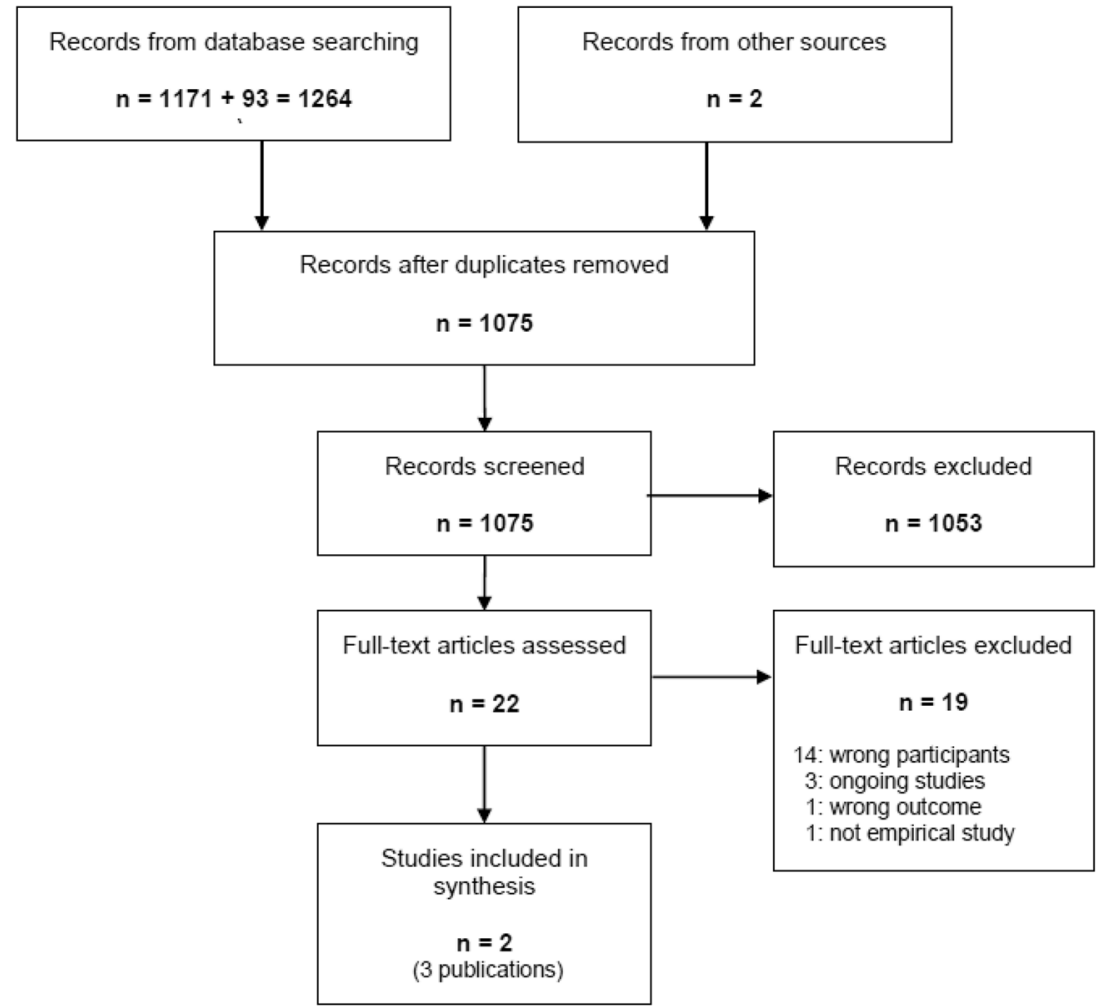


follow-up period, description of interventions, MI adherence and fidelity, primary and secondary outcomes and results. When data were missing, we contacted study authors to retrieve data.

The included studies were critically appraised by two authors (BEØ and FA) independently, using study specific appraisal checklists [23]. As the only studies meeting the inclusion criteria were RCTs, we used the Cochrane Risk of Bias tool [24]. The judgements of 'low risk', 'high risk' or 'unclear risk' were made for the domains: selection bias, performance bias, detection bias, attrition bias, reporting bias and other bias. We also made a total summary assessment for each study. Papers using data from the same study were appraised as one. Differences in opinion were solved through discussion and re-examination of the studies.

We synthesized the data from the included studies and presented the results narratively and in tables.

\section{Results}

\section{Search Results}

The searches identified 1264 records, of which 1262 were identified through the database searches, one through cited reference searches in Web of science and one through hand searches of the MINT bulletin (Supplementary material: Appendix I). After duplicates were removed, 1075 records remained, and 1053 of these were excluded after screening of titles and abstracts (Fig. 1). Of the 22 publications examined in full-text, 14 were excluded either because less than $50 \%$ of the study population had musculoskeletal disorders, or because the proportion of people with these types of disorders in the study sample was not described. Three ongoing studies were excluded due to no published results; one was excluded because it did not have return to work as an aim for the MI intervention, and one because it lacked empirical data (Supplementary material: Appendix II). Three papers from two studies met the inclusion criteria.

\section{Characteristics of Included Studies}

Two of the papers described a Canadian cluster RCT by Gross et al. [25], and Park et al. [26], including 728 claimants, injured at work, with chronic musculoskeletal conditions in different parts of the body. The third paper described a Norwegian RCT by Magnussen et al. including 89 disability pensioners with back pain [27] (Table 2). The two studies included 817 participants, with an average age between 45 and 49 years of whom $60 \%$ were male.

Both studies investigated the effect of MI on return to work, in combination with other interventions. In the Norwegian study, MI was provided as part of a brief group intervention and compared to usual follow-up from the social insurance and work office. The MI was aimed at helping the participants focus on their strength and capacities, identify barriers for returning to work, and search for ways to succeed in returning to work. In the Canadian study, the comparison group received usual follow-up, consisting of an individually tailored restoration program at a workers' compensation rehabilitation facility. The experimental group received individual MI conversations in addition to usual follow-up. The clinicians providing the MI were trained to listen for signs of ambivalence and to offer MI to those who were ambivalent about behaviour change. The clinicians decided the number and duration of the MI sessions (Table 2).

In the Norwegian study, a psychologist gave MI during a three-hour group session (information obtained from study author). There was no fidelity or adherence measurements related to the delivery of MI in this study nor any description of the psychologists MI competence. The clinicians giving the intervention in the Canadian study were occupational therapists and exercise therapist who had received 3 days of MI training by qualified MI instructors. They were given monthly coaching sessions during the intervention period. The clinicians completed an MI adherence checklist for each claimant. The checklist included registration of the fundamental processes used in MI and identification of a target behaviour for the MI session. Totally, MI was given to $26 \%$ of the claimants in the experimental group (Table 2).

\section{Critical Appraisal}

We rated the Norwegian study as having high risk of bias mainly due to lack of blinding of participants and intervention providers, small sample size and high drop out in the intervention group. The Canadian study was rated as having low risk of bias (Table 3 ).

\section{Main Findings from the Studies}

The results from the Norwegian study showed no effect on work related outcomes at 1-year follow-up [27]. Only one person in the MI group and two in the comparison group had returned to work at one-year follow-up. There was no statistically significant difference in being in a return to work process between the MI group and the control group (Table 4).

Results from the Canadian study showed that $12.1 \%$ more of the claimants, who were unemployed at baseline, had returned to work at discharge in the MI group compared to those receiving usual care only $(\mathrm{p}=0.03)$. There were no statistically significant difference in return to work between the MI group and the comparison group among those employed at baseline. At one-year follow-up, 
Table 2 Study characteristics

\begin{tabular}{|c|c|c|c|c|}
\hline $\begin{array}{l}\text { Author (year) } \\
\text { Context }\end{array}$ & $\begin{array}{l}\text { Sample size } \\
\text { Population }\end{array}$ & $\begin{array}{l}\text { Design } \\
\text { Participation } \\
\text { Drop-out }\end{array}$ & Interventions & MI training and fidelity \\
\hline Magnussen (2007) & $\mathrm{N}=89$ & RCT & Experimental: & Not described \\
\hline $\begin{array}{l}\text { No description of setting } \\
\text { Norway }\end{array}$ & $\begin{array}{l}\text { Disability pen- } \\
\text { sioners with } \\
\text { back pain } \\
\text { Disability pen- } \\
\text { sion }>1 \text { year, } \\
\text { mean } 8 \text { years } \\
65 \% \text { women } \\
\text { Mean age } 49 \text { (SD } \\
\text { 5.4) years } \\
\text { Range } \\
\text { 36-56 years }\end{array}$ & $\begin{array}{l}\text { Random assignment of partici- } \\
\text { pants } \\
\text { Experimental: } 45 \text { participants } \\
\text { Comparison: } 44 \text { participants } \\
\text { Participation: } 21 \% \\
\text { Dropout: } \\
\text { Experimental: } \mathrm{n}=4 \\
\text { Comparison: } \mathrm{n}=0 \\
16 \text { did not complete the interven- } \\
\text { tion but were included in the } \\
\text { analyses }\end{array}$ & $\begin{array}{l}\text { Brief vocational intervention pro- } \\
\text { gramme: } 2 \times 3 \mathrm{~h} \text {. group sessions } \\
\text { (5-11 in group) } \\
2 \mathrm{~h} \text {. information about spinal } \\
\text { problems + pain mechanisms } \\
1 \mathrm{~h} \text {. information from social insur- } \\
\text { ance and work office } \\
3 \mathrm{~h} \text {. MI } \\
\text { Medical examination and assess- } \\
\text { ment of work ability by physi- } \\
\text { cian and nurse } \\
\text { Follow-up from work office for } \\
\text { those motivated to RTW } \\
\text { Comparison: } \\
\text { Usual follow-up from social insur- } \\
\text { ance and work office }\end{array}$ & \\
\hline $\begin{array}{l}\text { Park et al. (2018) } \\
\text { Gross et al. (2017) } \\
\text { Workers' compensation } \\
\text { rehabilitation facility } \\
\text { Canada }\end{array}$ & $\begin{array}{l}\mathrm{N}=728 \\
\text { Claimants } \\
\text { with chronic } \\
\text { musculoskeletal } \\
\text { conditions } \\
\text { Mean duration: } \\
234 \text { days } \\
63 \% \text { men } \\
\text { Mean age } 45 \text { (SD } \\
12.2 \text { ) years } \\
73 \% \text { employed } \\
\text { Moderate pain } \\
\text { levels } \\
\text { Moderate dis- } \\
\text { ability }\end{array}$ & $\begin{array}{l}\text { Cluster RCT } \\
\text { Random assignment of } 12 \text { clini- } \\
\text { cians: } \\
\text { Experimental: ( } 367 \text { participants) } \\
4 \text { occupational therapists, } \\
2 \text { exercise therapists } \\
\text { Comparison: ( } 361 \text { participants) } \\
2 \text { occupational therapists, } \\
4 \text { exercise therapists } \\
\text { Participation: } \\
802 \text { claimants assessed, } 74 \\
\text { excluded: co-morbid condi- } \\
\text { tions ( }=12 \text { ) noncompliance/ } \\
\text { non compensable medical } \\
\text { reasons ( }=32 \text { ) attended pro- } \\
\text { gram }<5 \text { days ( } \mathrm{n}=30 \text { ) } \\
\text { No dropout of included clinicians } \\
\text { or participants }\end{array}$ & $\begin{array}{l}\text { Experimental: } \\
\text { Usual care at rehab centre }+ \text { indi- } \\
\text { vidual MI sessions number of } \\
\text { sessions decided by clinicians } \\
\text { (not reported) duration of MI } \\
\text { session from 10-50 min } \\
\text { Comparison: } \\
\text { Usual care at rehab centre: } \\
\text { Interdisciplinary rehabilita- } \\
\text { tion to improve work abilities } \\
\text { (4-6 weeks) } \\
\text { Individually tailored functional } \\
\text { restoration program including: } \\
\text { exercise, graded activity, RTW } \\
\text { planning, educational workshops } \\
\text { and individual counselling } \\
\text { (3-5 days per week, up to } 4 \mathrm{~h} \\
\text { per day) }\end{array}$ & $\begin{array}{l}\text { MI training: } \\
3 \text { full-day ses- } \\
\text { sions + monthly } \\
\text { coaching } \\
\text { MI fidelity: } \\
\text { Completion of MI } \\
\text { adherence checklist: } \\
\text { MI given to } 96 \text { of } 367 \\
\text { claimants }(26 \%) \\
\text { range: } 4-56 \%\end{array}$ \\
\hline
\end{tabular}

$R T W$ return to work, $M I$ motivaiontal interviewing

claimants in the MI group who were unemployed at baseline received 8 days more of partial temporary disability benefits than the comparison group $(\mathrm{p}=0.02)$, indicating that more claimants in the MI group had returned to modified work duties. The claimants in the MI group, who were employed at baseline, had $4.6 \%$ less recurrence of any type of benefits than the comparison group $(p=0.04)$ [25]. The effects in the Canadian study were significantly higher among the claimants of the MI adherent clinicians compared to the non-adherent clinicians. All the workers who were employed at baseline and treated by the MI adherent clinicians had returned to work at discharge. Among the claimants who were unemployed at baseline, three times as many of the clients who were treated by the MI adherent clinicians returned to work, compared to those receiving usual follow-up (Table 4).

\section{Discussion}

This is the first systematic mapping review of the evidence of MI to facilitate return to work for people with musculoskeletal disorders. We identified only three published papers from two RCTs. The RCTs had inconsistent results regarding the effect of MI on return to work for people with chronic musculoskeletal disorder. This is in line with previous systematic reviews which have shown that there are few studies on MI for people with chronic pain [13] and musculoskeletal disorders [12]. A meta-review from 2018 found moderate quality of evidence of the effectiveness of MI in promoting physical activity for people with chronic health conditions [28], while a systematic review from 2016 found small to moderate short-time effects of MI on treatment adherence and pain reduction for people with chronic 
Table 3 Risk of bias

\begin{tabular}{|c|c|c|}
\hline Bias & Judgement & Support for judgement \\
\hline \multicolumn{3}{|l|}{ Magnussen et al. [27], randomized controlled trial } \\
\hline Random sequence generation (selection bias) & Low & Computer-generated random list \\
\hline Allocation concealment (selection bias) & Low & Concealed random allocation \\
\hline Blinding of participants and personnel (performance bias) & High & Not possible to blind participants and personnel \\
\hline \multirow[t]{2}{*}{ Blinding of outcome assessment (detection bias) } & Low & $\begin{array}{l}\text { Primary outcome } 1 \text { : reduced disability pensions from register } \\
\text { data from National Insurance office }\end{array}$ \\
\hline & Unclear & $\begin{array}{l}\text { Primary outcome 2: being in a return to work process Self- } \\
\text { reported outcome on posted questionnaire, no information about } \\
\text { blinding of assessment }\end{array}$ \\
\hline Incomplete outcome data (attrition bias) & Unclear & Unclear if data were collected for dropouts \\
\hline Selective reporting (reporting bias) & Low & No published protocol, report results for all given outcomes \\
\hline Other bias & High & $\begin{array}{l}\text { Only } 29 / 45 \text { completed the intervention } \\
\text { Small sample size } \\
\text { No description of MI training or fidelity measurement }\end{array}$ \\
\hline Summary assessment & High & $\begin{array}{l}\text { Plausible bias that seriously weakens confidence in the results } \\
\text { because of lack of blinding of participants and personnel, small } \\
\text { sample size, low compliance to intervention and unsure fidelity } \\
\text { to MI intervention }\end{array}$ \\
\hline \multicolumn{3}{|c|}{ Gross et al. [25] and Park et al. [26], cluster randomized control trial } \\
\hline Random sequence generation (selection bias) & Low & $\begin{array}{l}\text { Clinicians were randomly allocated to intervention group or con- } \\
\text { trol group using a computerized random number generator }\end{array}$ \\
\hline Allocation concealment (selection bias) & Unclear & No information given regarding allocation concealment \\
\hline Blinding of participants and personnel (performance bias) & High & $\begin{array}{l}\text { Not possible to blind participants and personnel Participants were } \\
\text { unaware of the study and group membership }\end{array}$ \\
\hline Blinding of outcome assessment (detection bias) & Low & $\begin{array}{l}\text { Data were collected from Workers' Compensation Board Alberta } \\
\text { claims database by blinded outcome assessors }\end{array}$ \\
\hline Incomplete outcome data (attrition bias) & Low & $\begin{array}{l}\text { Available outcome measures for } 100 \% \text { of sample at time of dis- } \\
\text { charge and during 1-year follow-up }\end{array}$ \\
\hline Selective reporting (reporting bias) & Unclear & $\begin{array}{l}\text { All primary outcomes reported, no report of secondary outcomes } \\
\text { described in protocol } \\
\text { Protocol registered retrospectively }\end{array}$ \\
\hline Other bias & Low & No other bias identified \\
\hline Summary assessment & Low & $\begin{array}{l}\text { Plausible bias is unlikely to alter the results } \\
\text { Not possible to blind participants and personnel, but the main } \\
\text { outcome is not likely to be influenced by lack of blinding }\end{array}$ \\
\hline
\end{tabular}

pain [13]. Currently, there is limited evidence for the use of MI for people with musculoskeletal disorders due to the small amount and varying quality of studies [12].

There were several methodological differences across the two RCTs included in this mapping review. The Norwegian study included disability pensioners who had been away from work for an average of 8 years. In order to return to work after several years of absence, the disability pensioners might have to retrain and spend time searching for jobs [29]. At the one-year follow-up, twice as many in the experimental group reported being in a return to work process [27]. Some of these participants may have returned to work if the study follow-up period was longer. In addition, the study had a small sample size and only $64 \%$ in the intervention group completed the intervention. The study also lacked a description of the MI competence of the psychologist providing the intervention. For MI to be effective, the clinician should build a good working alliance [11] and elicit and amplify the persons change talk [30]. This may be challenging to accomplish during a single group session of MI even for a trained psychologist. Finally, MI was only one of several components of the brief group intervention, making it impossible to separate the effects of MI from the rest of the intervention.

In the Canadian study $73 \%$ of the study population were still employed at baseline and the mean time away from work for all the participants was less than one year. Among the claimants who were employed at baseline, there was a very high return to work rate both in the MI group and in the comparison group. This could have resulted in a ceiling 
Table 4 Main findings

\begin{tabular}{|c|c|}
\hline Paper & Results from primary outcomes \\
\hline Magnussen et al. (2007) & $\begin{array}{l}\left.\text { Reductions in disability pensions } \mathrm{s}^{\mathrm{r}} \text { (range in reductions: } 4-42 \%\right) \\
\text { Experimental group: } \mathrm{n}=1(2 \%) \text {, comparison group: } \mathrm{n}=2(4.5 \%) \text {, non-attendees: } \mathrm{n}=4(1 \%), n s \\
\text { In RTW process at one year follow up } \text { up }^{\mathrm{s}} \\
\text { Experimental group: } \mathrm{n}=10(22 \%) \text {, comparison group: } \mathrm{n}=5(11 \%) \text { RR } 1.96 \text { (95\% CI } 0.73-5.26) \\
\text { Power calculations: power of difference: } 19 \% \text {. Absolute risk reduction: } 11 \text {. Number needed to treat: } 9.2 \text { (95\% CI 3.4, } \\
\text { Inf) }\end{array}$ \\
\hline Park et al. (2018) & 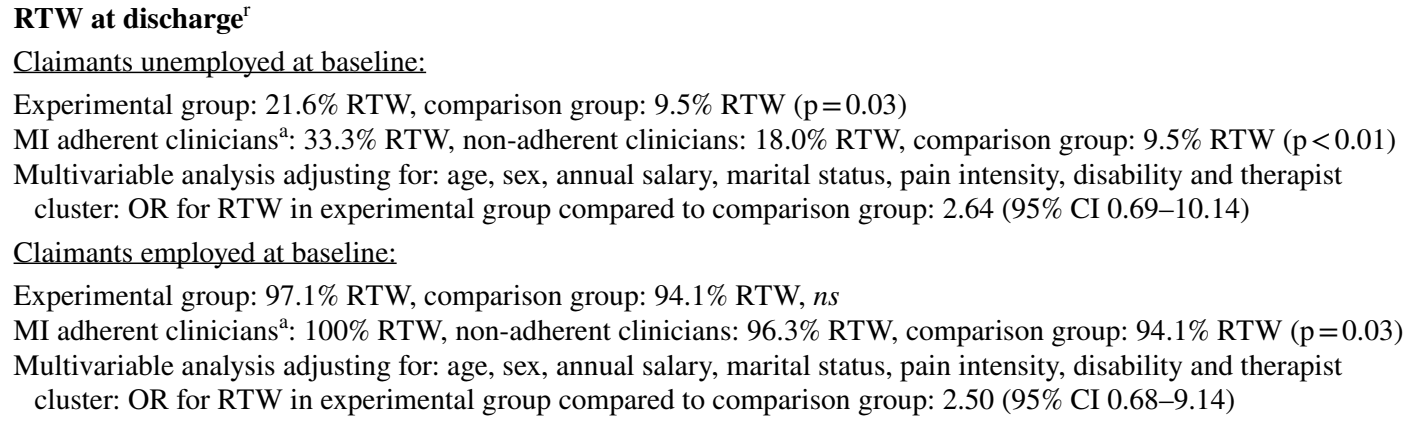 \\
\hline Gross et al. (2017) & 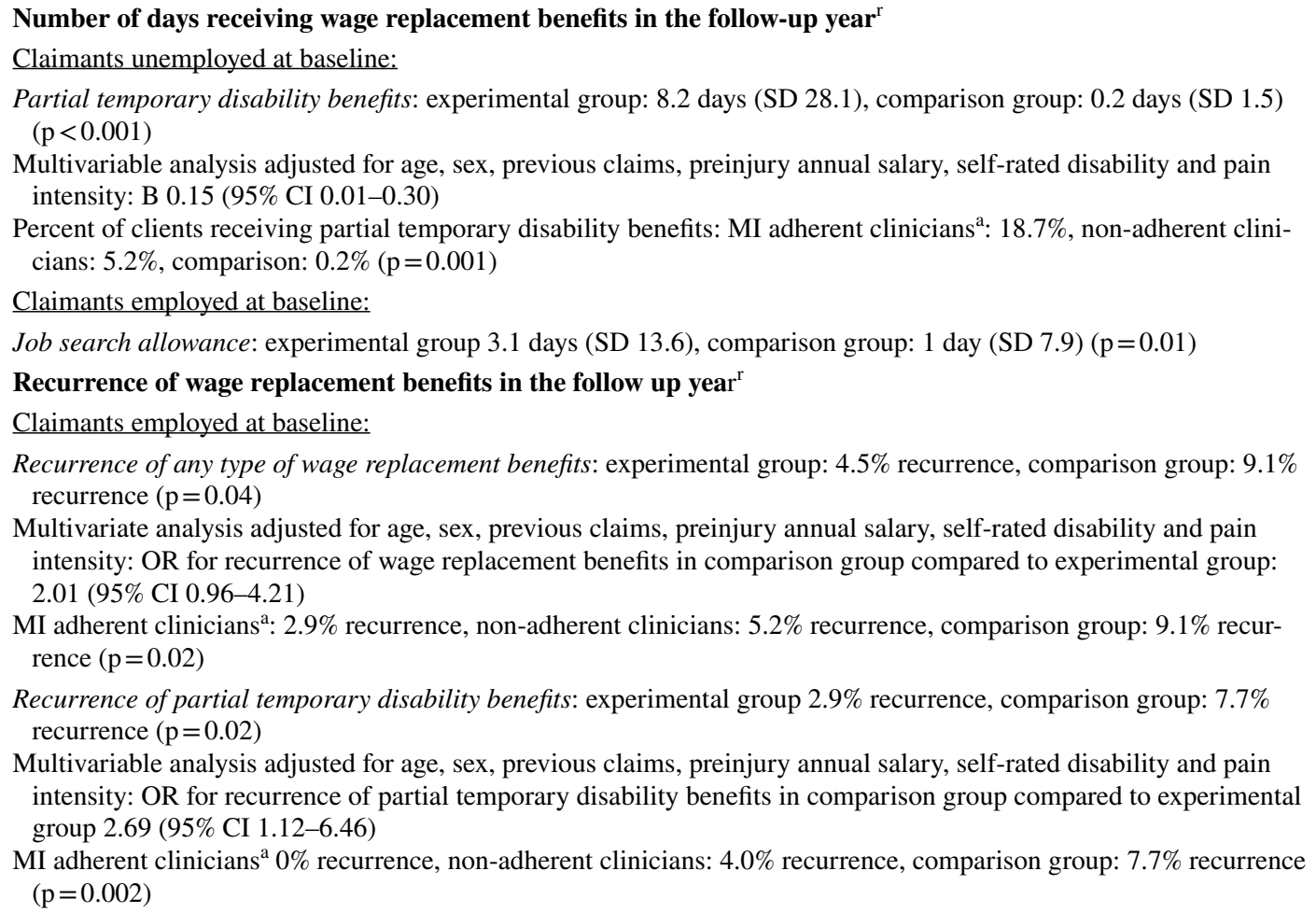 \\
\hline
\end{tabular}

${ }^{\mathrm{r}}=$ registry data, ${ }^{\mathrm{s}}=$ self-report, $R T W$ return to work, $n s$ not statistically significant difference, $R R$ relative risk

${ }^{\mathrm{a}}$ Clinicians documented MI use on adherence checklists

effect, making it hard to detect any benefit of the MI intervention. In addition, only one fourth of the claimants in the experimental group received $\mathrm{MI}$, which could have reduced the effectiveness of the intervention. Subgroup analyses showed that the effects on return to work in the MI group were highest among the claimants of the most MI adherent clinicians. This was the case both at discharge and at one-year follow-up among all the workers [25, 26]. The results suggest that the MI intervention might have been more effective if adherence had been higher among the clinicians. In the Canadian study the experimental group received $\mathrm{MI}$ in addition to usual follow-up, while the comparison group received usual follow-up only. We can 
therefore assume that MI contributed to the larger effect in the intervention group.

Surprisingly, the searches did not identify qualitative studies investigating how people with musculoskeletal disorders experience receiving MI to help them return to work, or how people who deliverer MI to people with musculoskeletal disorders experience the intervention. There are, however, several qualitative studies from the Swedish Dirigo project. In this project insurance officials were trained in MI to facilitate return to work for people on sick leave. Although these studies included people with all types of diagnoses, the results may be relevant for people with musculoskeletal disorders. Andersen and colleagues interviewed fourteen people on long term sick leave (mainly with mental disorders) about their experiences from the Dirigo project. The informants had positive experiences of MI because they felt the method helped them get to know themselves better, and become aware of opportunities for work and studies. They also felt that the insurance officials were making an effort to get to know them and their situation [31]. Two studies by Stahl and colleagues, from the same project, interviewed insurance officials in charge of following up people on sick leave $[32,33]$ and a study by Secker and Margrove investigated employment support workers experiences of MI [34]. These studies showed that the professionals were positive to MI and found it helpful in their work. However, they emphasized the need for support and ongoing assessment of MI skills in order to become confident in practicing MI and able to use the method in their work with clients. Lack of training, confidence and support in performing MI are common challenges reported by practitioners $[33,35]$.

Despite comprehensive literature searches by an experienced search specialist, one limitation of this review is that we might have missed grey literature. A strength of this review is its focus on musculoskeletal disorder as they are the main cause of disability. Another strength is the broad search strategy and inclusion criteria making it possible to include all relevant studies in the mapping review.

The current review has shown that there is a lack of research on MI for people with musculoskeletal disorders. In order to assess the effectiveness of MI on return to work for people with musculoskeletal disorders, we need more high-quality intervention studies. The studies should include adequate MI training for the persons delivering the intervention and assessment of their MI skills [13]. There appears to be increasing research interest in the use of MI in vocational rehabilitation. This review identified three ongoing trials including both qualitative and quantitative studies, and 14 publications on the use of $\mathrm{MI}$ in vocational rehabilitation for mixed populations of people with different conditions.

Although MI has been recommended as a method in vocational rehabilitation [10], the recommendations seem to be based primarily on theoretical papers describing the compatibility between MI, and aims and values in vocational rehabilitation $[9,18,35,36]$. The current review has revealed a huge research gap on the use of MI to facilitate return to work for people with musculoskeletal disorders. Only two efficacy studies of variable methodological quality, with conflicting results were available. Hence, more studies should be conducted before MI is implemented as a method to increase return to work for patients on sick leave with musculoskeletal disorders.

Acknowledgements Open Access funding provided by OsloMet - Oslo Metropolitan University. Information search specialist Lien Nguyen helped develop and performed all the searches in the electronic databases.

Author Contributions Margreth Grotle and Rigmor Berg had the idea for this article. Lien Nguyen and Fiona Aanesen performed the literature searches. Alexander Tingulstad, Ida Løchting and Fiona Aanesen screened the articles. Britt Elin Øiestad and Fiona Aanesen critically assessed the included articles. Margreth Grotle and Fiona Aanesen extracted data from the included studies. Fiona Aanesen drafted the paper and all authors critically revised the paper before approving publication.

Funding The Research Council of Norway, Project ID number: 280431.

\section{Compliance with Ethical Standards}

Conflict of interest Fiona Aanesen, Rigmor Berg, Ida Løchting, Alexander Tingulstad, Hedda Eik, Kjersti Storheim, Margreth Grotle and Britt Elin Øiestad declare that they have no conflict of interest.

Open Access This article is licensed under a Creative Commons Attribution 4.0 International License, which permits use, sharing, adaptation, distribution and reproduction in any medium or format, as long as you give appropriate credit to the original author(s) and the source, provide a link to the Creative Commons licence, and indicate if changes were made. The images or other third party material in this article are included in the article's Creative Commons licence, unless indicated otherwise in a credit line to the material. If material is not included in the article's Creative Commons licence and your intended use is not permitted by statutory regulation or exceeds the permitted use, you will need to obtain permission directly from the copyright holder. To view a copy of this licence, visit http://creativecommons.org/licenses/by/4.0/.

\section{References}

1. Global Burden of Disease Study 2013 Collaborators. Global, regional, and national incidence, prevalence, and years lived with disability for 301 acute and chronic diseases and injuries in 188 countries, 1990-2013: a systematic analysis for the Global Burden of Disease Study 2013. The Lancet. 2015;386(9995):743-800.

2. Global Alliance for Musculoskeletal Health of the Bone and Joint Decade. Available from: https://bjdonline.org/.

3. Toye F, Seers K, Allcock N, Briggs M, Carr E, Barker K. A synthesis of qualitative research exploring the barriers to staying in work with chronic musculoskeletal pain. Disabil Rehabil. 2016;38(6):566-572. 
4. Waddel G, Burton A. Is work good for your health \& well-beeing?: Commissioned by the Department for Work and Pensions. London: The Stationery Office; 2006.

5. Steenstra IA, Verbeek JH, Heymans MW, Bongers PM. Prognostic factors for duration of sick leave in patients sick listed with acute low back pain: a systematic review of the literature. Occup Environ Med. 2005;62(12):851-860.

6. Shaw L, Segal R, Polatajko H, Harburn K. Understanding return to work behaviours: promoting the importance of individual perceptions in the study of return to work. Disabil Rehabil. 2002;24(4):185-195.

7. Vogel N, Schandelmaier S, Zumbrunn T, Ebrahim S, de Boer WEL, Busse JW, et al. Return-to-work coordination programmes for improving return to work in workers on sick leave. Cochrane Database Syst Rev. 2017. https://doi.org/10.1002/14651858. CD011618.pub2.

8. Page KM, Tchernitskaia I. Use of motivational interviewing to improve return-to-work and work-related outcomes: a review. Aust J Rehabil Couns. 2014;20(1):38-49.

9. Manthey T, Jackson C, Evans-Brown P. Motivational interviewing and vocational rehabilitation: a review with recommendations for administrators and counselors. J Appl Rehabil Couns. 2011;42(1):3-14.

10. Leahy MJ, Del Valle RJ, Landon TJ, Iwanaga K, Sherman SG, Reyes A, et al. Promising and evidence-based practices in vocational rehabilitation: results of a national Delphi study. J Vocat Rehabil. 2018;48(1):37-48.

11. Miller WR, Rollnick S. Motivational interviewing. Helping people change. 3rd ed. New York: The Guilford Press; 2013.

12. Chilton R, Pires-Yfantouda R, Wylie M. A systematic review of motivational interviewing within musculoskeletal health. Psychol Health Med. 2012;17(4):392-407.

13. Alperstein $\mathrm{D}$, Sharpe L. The efficacy of motivational interviewing in adults with chronic pain: a meta-analysis and systematic review. J Pain. 2016;17(4):393-403.

14. Torres A, Frain M, Tansey TN. The impact of motivational interviewing training on rehabilitation counselors: assessing working alliance and client engagement. A randomized controlled trial. Rehabil Psychol. 2019;64(3):328-338.

15. Grant M, O-Beirne-Elliman J, Froud R, Underwood M, Seers K. The work of return to work. Challenges of returning to work when you have chronic pain: a meta-ethnography. J Open. 2019. https:// doi.org/10.1136/bmjopen-2018-025743.

16. Holland $\mathrm{P}$, Clayton S. Navigating employment retention with a chronic health condition: a meta-ethnography of the employment experiences of people with musculoskeletal disorders in the UK. Disabil Rehabil. 2016. https://doi.org/10.1080/09638 288.2018.1519041.

17. Flodgren GM, Berg RC. Motivational interviewing as a method to facilitate return to work: a systematic review. Report-2017. Oslo: National Institute of Public Health; 2017.

18. Park J, Gross DP, Rayani F, Norris CM, Roberts MR, James C, et al. Model of Human Occupation as a framework for implementation of Motivational Interviewing in occupational rehabilitation. Work. 2019;62(4):629-641.

19. Higgins JPT, Green S, editors. Cochrane Handbook for Systematic Reviews of Interventions Version 5.1.0: The Cochrane Collaboration. New York: Wiley; 2011.

20. Arksey H, O'Malley L. Scoping studies: towards a methodological framework. Int J Soc Res Methodol. 2005;8(1):19-32.

21. Levac D, Colquhoun H, O'Brien K. Scoping studies: advancing the methodology. Implement Sci. 2010;5(1):69.
22. Tricco AC, Lillie E, Zarin W, O'Brien KK, Colquhoun H, Levac D, et al. PRISMA Extension for Scoping Reviews (PRISMA-ScR): checklist and explanation. Ann Intern Med. 2018;169(7):467.

23. Aanesen F. Motivational interviewing as a method to facilitate return to work for people with musculoskeletal disorders: Protocol for a systematic mapping review: Musk health research group Oslo Metropolitan University. 2019. Available from: https://www. muskhealth.com/protocol-systematic-mapping-review.

24. Higgins JP, Altman DG, Sterne JAC. Assessing risk of bias in included studies. In: Higgins JPT, Green S, editors. Cochrane Handbook for Systematic Reviews of Interventions Version 5102011.

25. Gross DP, Park J, Rayani F, Norris CM, Esmail S. Motivational interviewing improves sustainable return to work in injured workers after rehabilitation: a cluster randomized controlled mal. Arch Phys Med Rehabil. 2017;98(12):2355-2363.

26. Park J, Esmail S, Rayani F, Norris CM, Gross DP. Motivational Interviewing for workers with disabling musculoskeletal disorders: results of a cluster randomized control trial. J Occup Rehabil. 2018;28(2):252-264.

27. Magnussen L, Strand LI, Skouen JS, Eriksen HR. Motivating disability pensioners with back pain to return to work-a randomized controlled trial. J Rehabil Med. 2007;39(1):81-87.

28. Frost H, Campbell P, Maxwell M, O'Carroll RE, Dombrowski SU, Williams B, et al. Effectiveness of Motivational Interviewing on adult behaviour change in health and social care settings: a systematic review of reviews. PLoS ONE. 2018. https://doi. org/10.1371/journal.pone.0204890.

29. Saunders SL, Maceachen E, Nedelec B. Understanding and building upon effort to return to work for people with long-term disability and job loss. Work. 2015;52(1):103.

30. Romano M, Peters L. Understanding the process of motivational interviewing: a review of the relational and technical hypotheses. Psychother Res. 2016;26(2):220-240.

31. Andersen A, Stahl C, Anderzen I, Kristiansson P, Larsson K. Positive experiences of a vocational rehabilitation intervention for individuals on long-term sick leave, the Dirigo project: a qualitative study. BMC Public Health. 2017;17(1):790.

32. Stahl C, Andersen A, Anderzen I, Larsson K. Process evaluation of an interorganizational cooperation initiative in vocational rehabilitation: the Dirigo project. BMC Public Health. 2017;17(1):431.

33. Stahl C, Gustavsson M. Introducing motivational interviewing in a sickness insurance context: translation and implementation challenges. J Occup Rehabil. 2018;28(2):357-364.

34. Secker J, Margrove KL. Employment support workers' experiences of motivational interviewing: results from an exploratory study. Psychiatr Rehabil J. 2014;37(1):65-67.

35. Lloyd C, Tse S, Waghorn G, Hennessy N. Motivational interviewing in vocational rehabilitation for people living with mental ill health...including commentary by Scales R. Int J Ther Rehabil. 2008;15(12):572-579.

36. Wagner CC, McMahon BT. Motivational interviewing and rehabilitation counseling practice. Rehabil Couns Bull. 2004;47(3):152-191.

Publisher's Note Springer Nature remains neutral with regard to jurisdictional claims in published maps and institutional affiliations. 